\title{
The Oxidative Stress May be Induced by the Elevated Homocysteine in Schizophrenic Patients
}

\author{
Anna Dietrich-Muszalska $\cdot$ Joanna Malinowska \\ Beata Olas · Rafal Głowacki • Edward Bald • \\ Barbara Wachowicz · Jolanta Rabe-Jabłońska
}

Received: 13 October 2011/Revised: 3 January 2012 / Accepted: 10 January 2012/Published online: 24 January 2012

(C) The Author(s) 2012. This article is published with open access at Springerlink.com

\begin{abstract}
The mechanisms of oxidative stress in schizophrenic patients are not fully understood. In the present study, we investigated the effect of elevated level of homocysteine (Hcys) on some parameters of oxidative stress, namely thiobarbituric acid reactive substances (TBARS), an index of lipid peroxidation in plasma, the level of carbonyl groups in plasma proteins, as well as the amount of 3-nitrotyrosine in plasma proteins isolated from schizophrenic patients. Patients hospitalised in I and II Psychiatric Department of Medical University in Lodz, Poland were interviewed with special questionnaire (treatment, course of diseases, dyskinesis and other EPS). According to DSM-IV criteria all patients had diagnosis of paranoid type. They were treated with antipsychotic drugs (clozapine, risperidone, olanzapine). Mean time of schizophrenia duration was about 5 years. High-performance liquid chromatography was used to analyse the total level of homocysteine in plasma. Levels of carbonyl groups and 3-nitrotyrosine residues in plasma proteins were measured by ELISA and a competition ELISA, respectively. The lipid peroxidation in plasma was measured by the level of TBARS. Our results showed that in schizophrenic patients the amount of homocysteine in plasma was higher in comparison with the control
\end{abstract}

\footnotetext{
A. Dietrich-Muszalska · J. Rabe-Jabłońska

Department of Affective and Psychotic Disorders, Medical University of Lodz, Czechoslowacka 8/10, 92-216 Lodz, Poland e-mail: tzn_lodz@post.pl

J. Malinowska $\cdot$ B. Olas $(\bowtie) \cdot$ B. Wachowicz

Department of General Biochemistry, University of Lodz, Pomorska 141/3, 90-236 Lodz, Poland

e-mail: olasb@biol.uni.lodz.pl

R. Głowacki · E. Bald

Department of Environmental Chemistry, University of Lodz, Pomorska 163, 90-236 Lodz, Poland
}

group. We also observed a statistically increased level of biomarkers of oxidative/nitrative stress such as carbonyl groups or 3-nitrotyrosine in plasma proteins from schizophrenic patients. Moreover, our experiments indicate that the correlation between the increased amount of homocysteine and the oxidative stress exists. Considering the data presented in this study, we suggest that the elevated Hcys in schizophrenic patients may stimulate the oxidative stress.

Keywords Schizophrenic disorders - Oxidative stress . Carbonyl group $\cdot 3$-nitrotyrosine $\cdot$ Homocysteine

\section{Introduction}

In schizophrenic patients dysregulation of reactive oxygen species (ROS) and reactive nitrogen species (RNS) metabolism, as detected by abnormal activities of critical antioxidant enzymes and other indicators-lipid peroxidation in plasma, red blood cells, blood platelets, and cerebrospinal fluid is observed [1-3]. Such abnormalities have been associated with tardive dyskinesia, negative symptoms, neurological signs and poor premorbid function. $\mathrm{Li}$ et al. [4] also suggest that excess ROS formation may play a critical role in the etiology of schizophrenia. A cell membrane dysfunction caused by lipid peroxidation can be secondary to a free radical-mediated pathology and may contribute to specific aspects of schizophrenic symptomatology and complications of its treatment. Our earlier studies by using different specific biomarkers of oxidative stress, including activity of platelet antioxidative enzyme - superoxide dismutase (SOD) revealed that in blood platelets from schizophrenic patients oxidative stress occurs [3]. We have presented that suppressed SOD activity in blood platelets from schizophrenic patients is 
associated with enhanced ROS generation and lipid peroxidation when compared with healthy control [3]. We also observed, that the level of isoprostanes (indicators of oxidative stress) in schizophrenic patients in acute period of psychosis is extremely high compared with control group [5], and our results indicate that in schizophrenic patients increased production of isoprostanes reflects oxidative stress and oxidative damage of lipids.

The modification of proteins plays an essential role in the pathogenesis of various diseases, including vascular complications, inflammatory and mental disorders. Our earlier results showed that the level of biomarkers of oxidation/nitration proteins in plasma of schizophrenic patients (in acute period of psychosis) is distinctly higher than in plasma of healthy subjects [6]. Moreover, in schizophrenic patients reduced status of plasma total antioxidant capacity was observed [7]. Our earlier results reported the changes of the level of low-molecular-weight thiols such as glutathione, cysteine and cysteinylglycine (which are physiological free radical scavengers) in plasma from schizophrenic patients, whereas the level of homocysteine (Hcys) was significantly elevated in plasma of schizophrenic patients in acute period of psychosis [6]. Because on the basis of various observations, it is proposed that Hcys may act as an oxidant in the model system in vitro and in vivo $[8,9]$, the aim of our present study was to explain the effect of the elevated Hcys on the selected parameters of oxidative stress (carbonyl groups and 3-nitrotyrosine levels in proteins and thiobarbituric acid reactive substances (TBARS) - a biomarker of lipid peroxidation) of plasma from schizo phrenic patients. Oxidative/nitrative changes in proteins include carbonyl groups formation and 3-nitrotyrosine generation. Nitration of tyrosine residues by nitric oxide-derived species results in the accumulation of 3-nitrotyrosine in proteins. Tyrosine nitration is also a biomarker of oxidative damage induced by peroxynitrite. Other protein modification mediated by free radical is protein carbonylation, which is a non enzymatic addition of aldehydes or ketones to specific amino acid residues.

\section{Materials and Methods}

\section{Materials}

Sheep anti-nitrotyrosine polyclonal antibodies were from Oxis (Portland, USA). Biotyninylated anti-goat/mouse/ rabbit antibody and streptavidin-biotynylated horseradish peroxidase were from DAKO (Glostrup, Denmark). All other reagents were of analytical grade and were provided by commercial suppliers.
Table 1 Clinical characteristics of patients with schizophrenia and healthy volunteers subjects

\begin{tabular}{lll}
\hline & $\begin{array}{l}\text { Patients with } \\
\text { schizophrenia } \\
(n=19)\end{array}$ & $\begin{array}{l}\text { Control } \\
\text { subject } \\
(n=19)\end{array}$ \\
\hline Sex, M/F & $11 / 8$ & $15 / 4$ \\
Age (years) & $30.4 \pm 3.2$ & $30.0 \pm 3.1$ \\
Duration of illness (years) & $8.4 \pm 4.3$ & $\mathrm{NS}$ \\
PANSS & $68.3 \pm 13.6$ & $\mathrm{NS}$ \\
PANSS-positive symptom scores & $11.2 \pm 4.1$ & $\mathrm{NS}$ \\
PANSS-negative symptom scores & $19.7 \pm 5.8$ & $\mathrm{NS}$ \\
\hline
\end{tabular}

The Criteria of Schizophrenic Patients Inclusion

The studied population of schizophrenic patients comprised 19 patients between the ages of 25-36 years (mean 30, $4 \pm 3.2$ ) who were hospitalized in I and II Psychiatric Department of Medical University in Lodz, Poland. All subjects were interviewed with special questionnaire (treatment, course of diseases, dyskinesis and other extrapyramidal syndromes) and according to DSM-IV criteria [10] all patients had diagnosis of paranoid type. They were treated with antipsychotic drugs (clozapine, risperidone, olanzapine) during therapy. They did not use addictive antidepressants or mood stabilizers. Mean time of schizophrenia duration was 5 years. Table 1 present clinical characteristics of patients with schizophrenia.

The Criteria of Volunteers Inclusion

Blood samples were taken from 19 healthy volunteers (males and females) aged between 25 and 35 years (mean $30 \pm 3.1$ ). Blood samples were taken from healthy subjects without psychiatric, neurological or somatic disorders and history of head injuries, allergy and lipid or carbohydrate metabolism disorders, untreated with drugs. Healthy subjects did not use addictive substances and antioxidant supplementation, their diet was balanced (meat and vegetables), lived in similar socio-economic conditions. Subjects with significant medical illness were excluded.

\section{Qualification Questionnaire}

Structured medical interviews were carried out, considering both mental and physical status, medical history, alimentary habits and substance use. The following exclusion criteria were applied: any somatic disorders, especially circulatory diseases, disorders of lipid metabolism and diabetes, malnutrition and neurological diseases serious head injuries mental disorders either in volunteers or their 
families use of any medications or addictive substances, unbalanced diet antioxidant supplementation psychiatric examination (using the M.I.N.I.-Mini International Neuropsychiatric Interview [11]) neurological and somatic examinations. Laboratory tests: lipid panel (total cholesterol, LDL, HDL, triglycerides) and glucose.

The protocol was passed by the Committee for Research on Human Subjects of the Medical University of Lodz number RNN/899/2000.

All patients and volunteers included in the study have been informed about aims of the study and methods implemented and expressed their written informed consent for participation in this study.

\section{Isolation of Plasma}

Human blood from schizophrenic patients and healthy volunteers was collected into sodium citrate $(5 \mathrm{mM}$ final concentration) and immediately centrifuged $(3,000 \times g$, $15 \mathrm{~min}$ ) to get plasma.

\section{Evaluation of Lipid Peroxidation Level}

Samples of plasma (from schizophrenic patients and healthy volunteers) were transferred to an equal volume of $20 \%(\mathrm{v} / \mathrm{v})$ cold trichloroacetic acid in $0.6 \mathrm{M} \mathrm{HCl}$ and centrifuged at $1,200 \times \mathrm{g}$ for $15 \mathrm{~min}$. One volume of clear supernatant was mixed with 0.2 volume of $0.12 \mathrm{M}$ thiobarbituric acid in $0.26 \mathrm{M}$ Tris at $\mathrm{pH} 7.0$ and immersed in a boiling water bath for $15 \mathrm{~min}$. Absorbance at $532 \mathrm{~nm}$ was measured and results were expressed as nmoles of TBARS [12].

Determination of 3-Nitrotyrosine in the Plasma Proteins by a C-ELISA Method

Detection of 3-nitrotyrosine-containing proteins by a competition ELISA (C-ELISA) method in plasma (from schizophrenic patients and healthy volunteers) was performed according to the procedure of Khan et al. [13] as described previously [14]. The nitro-fibrinogen (at concentration of $0.5 \mu \mathrm{g} / \mathrm{ml}$ and 3-6 mol nitrotyrosine/mol protein) was prepared for use in the standard curve. The linearity of the C-ELISA method was confirmed by the construction of a standard curve ranging from 10 to $500 \mathrm{nM}$ nitrotyrosinefibrinogen equivalent. The concentrations of nitrated proteins that inhibit anti-nitrotyrosine antibody binding were estimated from the standard curve and are expressed as nitro$\mathrm{Fg}$ equivalents. The amount of nitrotyrosine present in fibrinogen after treatment with peroxynitrite (at final concentration of $1 \mathrm{mM}$ ) was determined spectrophotometrically (at $\mathrm{pH} 11.5, \varepsilon_{430 \mathrm{~nm}}=4,400 \mathrm{M}^{-1} \mathrm{~cm}^{-1}$ ).
Detection of Carbonyl Groups in the Plasma Proteins by ELISA Method

Detection of carbonyl groups by ELISA method (using anti-DNP antiobodies) in plasma (from schizophrenic patients and healthy volunteers) was carried out according to a method described by Buss et al. [15] as described previously [14]. Human plasma proteins reacted with dinitrotrophenylhydrazine (DNP) and then proteins were non-specifically adsorbed to an ELISA plate. The peroxynitrite treated-fibrinogen (10 nmol of carbonyl groups $/ \mathrm{mg}$ of fibrinogen) was prepared for use in the standard curve. The linearity of the ELISA method was confirmed by the construction of a standard curve ranging form 0.1 to 10 nmol carbonyl groups/mg of fibrinogen. The amount of carbonyl groups present in fibrinogen after treatment with peroxynitrite (at final concentration of $1 \mathrm{mM}$ ) was determined spectrophotometrically as described Levine et al. [16].

\section{Determination of Homocysteine in Plasma}

The classical technique High-performance liquid chromatography (HPLC) has been used to analysis of homocysteine from human plasma (from schizophrenic patients and healthy volunteers). HPLC analysis was performed with a Hewlett-Packard 1100 Series system according to Głowacki et al. [17] and Bald et al. [18].

\section{Statistical Analyses}

All the values in this study were expressed as mean \pm SD. In order to eliminate uncertain data, Grubbs test was performed. The statistically significant difference between the control group and schizophrenic patients was done by Mann-Whitney test using StatSoft Inc. "Statistica" v. 6.0. Regression line was calculated by means of the leastsquares method.

\section{Results}

Using HPLC method we determined in human plasma the levels of homocysteine. Our studies have shown that the level of homocysteine in plasma from schizophrenic patients was significantly higher (about 55\%) than in plasma obtained from healthy volunteers (Table 2). We have also observed that the level of different biomarkers of oxidative stress in plasma from schizophrenic patients differs from their level in plasma obtained from healthy volunteers (Table 2). The level of carbonyl groups (determined by ELISA method) in plasma proteins from schizophrenic patients was significantly higher than the 
Table 2 Changes of the total level of homocysteine and the level of selected biomarkers of oxidative stress in plasma of healthy subjects and schizophrenic patients

\begin{tabular}{lllll}
\hline & $\begin{array}{l}\text { The total level } \\
\text { of homocysteine } \\
(\mu \mathrm{M})\end{array}$ & $\begin{array}{l}\text { The level of carbonyl } \\
\text { groups in plasma proteins } \\
\text { (nmol carbonyl groups/mg } \\
\text { of plasma proteins) }\end{array}$ & $\begin{array}{l}\text { The level of 3-nitrotyrosine } \\
\text { in plasma proteins } \\
\text { (nmol 3-nitrotyrosine/mg } \\
\text { of plasma proteins) }\end{array}$ & $\begin{array}{l}\text { The level of TBARS } \\
\text { (nmol TBARS/ml } \\
\text { of plasma) }\end{array}$ \\
\hline Healthy subjects & $6.163 \pm 0.508$ & $0.178 \pm 0.017$ & $0.0075 \pm 0.0013$ & $1.109 \pm 0.083$ \\
Schizophrenic patients & $\begin{array}{l}13.010 \pm 1.082 \\
\left(P=1.96 \times 10^{-6}\right)\end{array}$ & $\begin{array}{l}0.482 \pm 0.065 \\
\left(P=3.1 \times 10^{-4}\right)\end{array}$ & $\begin{array}{c}0.044 \pm 0.0072 \\
\left(P=3.6 \times 10^{-6}\right)\end{array}$ & $\begin{array}{l}1.655 \pm 0.105 \\
\left(P=1.6 \times 10^{-4}\right)\end{array}$ \\
\hline
\end{tabular}

The results are representative of independent experiments in triplicate and expressed as a mean $\pm \mathrm{SD}$. The statistical analysis of difference between the tested groups was done using Mann-Whitney test

A

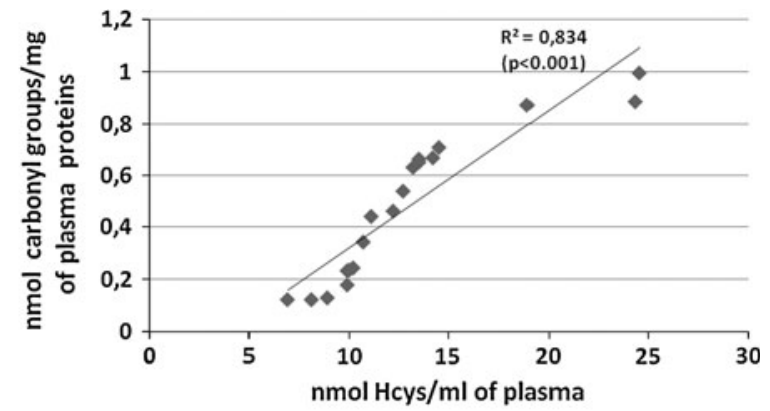

B

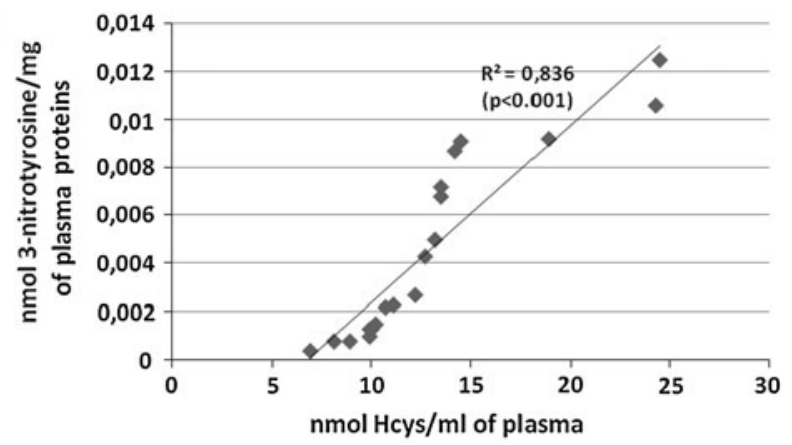

C

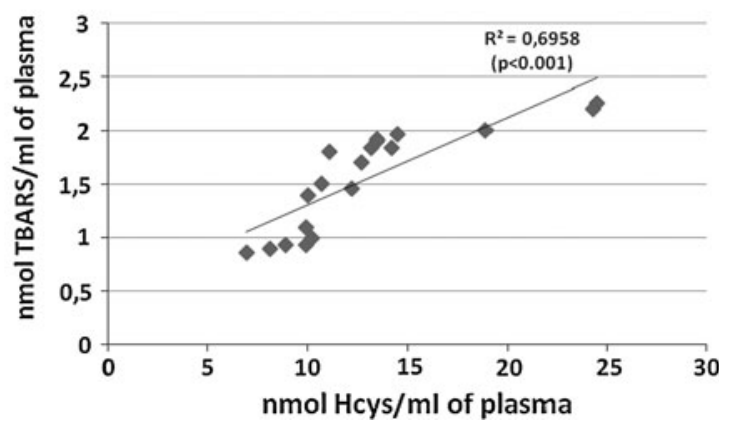

Fig. 1 The correlation between the selected parameters of oxidative stress [the level of carbonyl groups (a), the level of 3-nitrotyrosine (b), the level of TBARS (c)] and the total level of homocysteine in plasma obtained from schizophrenic patients. Regression line was calculated by means of the least-squares method

level of carbonylation in plasma obtained from healthy volunteers (Table 2). In plasma proteins from schizophrenic patients the amount of 3-nitrotyrosine as determined by a competition C-ELISA method was also higher than in control group (Table 2). We have observed the same process when we measured the lipid peroxidation (Table 2).

The correlation between the increased amount of Hcys and changes in the level of various biomarkers of oxidative stress in plasma from schizophrenic patients is presented in Fig. 1.

\section{Discussion}

L-Homocysteine is an endogenous amino acid, containing the free thiol group, which in healthy cells is involved in methionine and cysteine synthesis/resynthesis. Indirectly, Hcys participates in methyl, folate, and cellular thiols metabolism [19]. Approximately $80 \%$ of total plasma Hcys is protein bound, and only a small amount exists as a free reduced Hcys (about $0.1 \mu \mathrm{M}$ ). The majority of the unbound portion of Hcys is oxidized to form dimers (homocystine) or combined with cysteine to form mixed disulphides [20,21]. Elevated concentrations of homocysteine in human tissues, definied as hyperhomocysteinemia have been correlated with some diseases, such as cardiovascular, neurodegenerative, and kidney disorders. The elevated level of homocysteine has been repeatedly observed in patients with schizophrenia [6, 22-24]. Molecular-genetic studies revealed tha association between schizophrenia and polymorphisms of two genes-methylenetetrahydrofolate reductase and cystathionine-beta-synthase involved in the conversion of homocysteine to methionine and cysteine, respectively [23]. Haidemenos et al. [25] also observed that patients in chronic schizophrenia had increased the amount of plasma homocysteine compared to control, but this increase in plasma homocysteine is not related to plasma folate and vitamin $B_{12}$ levels. In the Tunisian population, hyperhomocysteinemia in schizophrenia seems to be linked to vitamin $\mathrm{B}_{12}$ deficiency, likely caused by a lack of dietary animals proteins [22]. Results of Kim and Moon [24] showed that Korean schizophrenic patients with high serum 
homocysteine levels may have the genetic defect of having low folate serum levels.

Increased concentration of homocysteine in the blood may not only be an independent risk factor for atherosclerotic disease, deep vein thrombosis and thromboembolism, and may promote also cerebrovascular diseases. Bleich et al. [26] and Sachdev et al. [27] showed a significant positive relationship between plasma homocysteine levels and brain atrophy. Brown et al. [28] suggest that elevated third-trimester homocysteine levels may increase schizophrenia risk through developmental effects on brain structure and function and/or through subtle damage to the placental vasculature that compromises oxygen delivery to the fetus. Results of Song et al. [29] showed that homocysteine metabolism and monoaminergic neurotransmitter systems are important in schizophrenia pathology. They hypothesized that the gene PNPO (pyridoxine 5'-phosphatase oxidase gene) might be a candidate for susceptibility to schizophrenia because PNPO encodes pyridoxamine $5^{\prime}$-phosphate oxidase (EC 1.4.3.5), a rate-limiting enzyme in pyridoxal 5 '-phosphate (PLP, vita$\min \mathrm{B}(6))$ synthesis. PLP is a metabolically-active form of vitamin $\mathrm{B}(6)$ and thus, is required as a co-factor for enzymes involved in both homocysteine metabolism and synthesis of neurotransmitters such as catecholamine. Moreover, some results suggest that association of homocysteine with schizophrenia may involve the glutamatergic system [3032]. Homocysteine may act as an antagonist at the glycine site of the NMDA receptor (in the presence of normal or low glycine levels) or it may act as an agonist at the glutamate site of this receptor (when glycine levels are increased) [32]. Homocysteine may also enhance oxidative stress $[31,33]$. Our earlier [3,5] and present results (Table 2) or the results of Yao et al. [34] suggest that schizophrenia is characterized by abnormal oxidative stress. The present study provides more information about the mechanisms of oxidative stress in schizophrenic patients. The first time, our results showed that the elevated level of Hcys may play an important role in the oxidative stress in schizophrenic patients (in an acute period of psychosis; Fig. 1). Experiments presented here showed that the correlation between the increased amount of Hcys and the oxidative stress in plasma from schizophrenic patients exists (Fig. 1). It should be underlined that in our present study all schizophrenic patients were treated with second-generation anti-psychotic drugs, which do not induce the oxidative stress in different elements of blood, including blood platelets and plasma [35, 36]. However, typical antipsychotic drugs (chlorpromazine) may play a role as modifying factor for folate metabolism in chronic schizophrenic patients [37], but in our present experiments patients were treated with other antipsychotic drugs (clozapine, risperidone, olanzapine) during therapy. Moreover, results of Henderson et al. [38] did not show association with secondgeneration anti-psychotic drugs (clozapine, risperidone, olanzapine) and Hcys levels in schizophrenic patients. Experiments of Neeman et al. [39] also demonstrated that plasma levels of amino acids, including Hcys in normal subjects and patients treated with these drugs did not differ significantly.

On the basis of various observations, it proposed that diet polyphenolic antioxidants can inhibit the oxidative stress induced by Hcys [8, 40], therefore the next step of future studies is to evaluate the role of different antioxidants in the oxidative stress in schizophrenic patients, which have the elevated Hcys.

Acknowledgments Supported by the grant 502-11-176 from Medical University of Lodz, Poland and by the grant 545/244 from University of Lodz, Poland.

\section{Conflict of interest None.}

Open Access This article is distributed under the terms of the Creative Commons Attribution Noncommercial License which permits any noncommercial use, distribution, and reproduction in any medium, provided the original author(s) and source are credited.

\section{References}

1. Reddy RD, Yao JK (1996) Free radical pathology in schizophrenia: a review. Prostaglandins Leukot Essent Fatty Acids 55: 33-34

2. Yao JK, Reddy R, Mcelhinny LG, Van Kammen DP (1998) Reduced status of plasma total antioxidant capacity in schizophrenia. Schizoph Res 32:1-8

3. Dietrich-Muszalska A, Olas B, Rabe-Jablonska J (2005) Oxidative stress in blood platelets from schizophrenic patients. Platelets 16:386-391

4. Li HC, Chen QZ, Ma Y, Zhou JF (2006) Imbalanced free radicals and antioxidant defense systems in schizophrenia: a comparative study. J Zhejian Univ Sci B 12:981-986

5. Dietrich-Muszalska A, Olas B (2007) Isoprostanes as indicators of oxidative stress in schizophrenia. World J Biol Psychiatry 14:1-6

6. Dietrich-Muszalska A, Olas B, Glowacki R, Bald E (2009) Oxidative/nitrative modifications of plasma proteins and thiols from patients with schizophrenia. Neuropsychobiology 59:1-7

7. Dietrich-Muszalska A, Kontek B (2007) Lipid peroxidation in patients with schizophrenia. Current Topics in Biophysics, Abstracts of the XIII Conference of Polish Biophysics Society, B-28

8. Carluccio MA, Ancora MA, Massaro M, Carluccio M, Scoditti E, Distante A, Storelli C, De Caterina R (2007) Homocysteine induces VCAM-1 gene expression through NF-kappaB and $\mathrm{NAD}(\mathrm{P}) \mathrm{H}$ oxidase activation: protective role of Mediterranean diet polyphenolic antioxidants. Am J Physiol Heart Circ Physiol 293:H2344-H2354

9. Olas B, Kedzierska M, Wachowicz B (2008) Comparative studies on homocysteine and its metabolite-homocysteine thiolactone action in blood platelets in vitro. Platelets 19:520-527

10. American Psychiatric Association (1994) Diagnostic and statistical manual of mental disorders, 4th edn. American Psychiatric Press, Washington

11. Sheehan DV, Lecrubier Y, Sheehan KH, Amorim P, Janavs J, Weiller E, Hergueta T, Baker R, Dunbar GC (1998) The MiniInternational Neuropsychiatric Interview (M.I.N.I.): the 
development and validation of a structured diagnostic psychiatric interview for DSM-IV and ICD-10. J Clin Psychiatry 59:22-33

12. Wachowicz B (1984) Adenine nucleotides in thrombocytes of birds. Cell Biochem Funct 2:167-170

13. Khan J, Brennan DM, Bradley N, Gao B, Brukdorfer R, Jacobs M (1998) 3-Nitrotyrosine in the proteins of human plasma determined by an Elisa method. Biochem J 330:795-801

14. Olas B, Nowak P, Kolodziejczyk J, Ponczek M, Wachowicz B (2006) Protective effects of resveratrol against oxidative/nitrative modifications of plasma proteins and lipids exposed to peroxynitrite. J Nut Biochem 17:96-102

15. Buss H, Chan TP, Sluis KB, Domigan NM, Winterbourn CC (1997) Protein carbonyl measurement by a sensitive ELISA method. Free Rad Biol Med 23:361-366

16. Levine RL, Garland D, Oliver CN, Amici A, Climent I, Lenz AG, Ahn BW, Shaltiel S, Stadtman ER (1990) Determination of carbonyl content in oxidatively modified proteins. Methods Enzymol 186:464-478

17. Glowacki R, Wójcik K, Bald E (2001) Facile and sensitive method for the determination of mesna in plasma by high-performance liquid chromatography with ultraviolet detection. J Chromatogr 914:29-35

18. Bald E, Chwatko G, Glowacki R, Kusmierek K (2004) Analysis of plasma thiols by high-performance liquid chromatography with ultraviolet detection. J Chromatogr 1032:109-115

19. D'Angelo A, Selhub J (1997) Homocysteine and thrombotic disease. Blood 90:1-11

20. Mansoor MA, Svardal AM, Ueland PM (1992) Determination of the in vivo redox status of cysteine, cysteinylglycine, homocysteine, and glutathione in human plasma. Anal Biochem 200:218-229

21. Ramakrishnan S, Sulochana KN, Lakshmi S, Selvi R, Angayarkanni K (2006) Biochemistry of homocysteine in health and diseases. Indian J Biochem Biophys 43:275-283

22. Bouaziz N, Ayedi I, Sidhom O, Kallel A, Rafrafi R, Jomaa R, Melki W, Feki M, Kaabechi N, El Hechmi Z (2010) Plasma homocysteine in schizophrenia: determinants and clinical correlations in Tunisian patients free from antipsychotics. Psychiatry Res 179:24-29

23. Golmbet VE, Lebedeva IS, Alfimova MV, Barkhatova AN, Lezheiko TV, Kolesina NIU, Borozdina SA, Abramova LI (2010) Homocysteine-related genes and attention in patients witch schizophrenia and schizoaffective psychosis. Zh Nevrol Psikhiatr Im S S Korsakova 110:86-89

24. Kim TH, Moon SW (2011) Serum homocysteine and folate levels in Korean schizophrenic patients. Psychiatry Invest 8:134-140

25. Haidemenos A, Kontis D, Kallai E, Allin M, Lucia B (2007) Plasma homocysteine, folate and B12 in chronic schizophrenia. Prog Neuropsychopharmacol Biol Psychiatry 15:1289-1296

26. Bleich S, Junemann A, Von Ahsen N, Lausen B, Ritter K, Beck G, Naumann GO, Kamhuber J (2002) Homocysteine and risk of open-angle glaucoma. J Neural Transm 109:1499-1504

27. Sachdev PS, Valenzuela M, Wang XL, Looi JC, Brodaty H (2002) Relationship between plasma homocysteine levels and brain atrophy in healthy elderly individuals. Neurology 58:1539-1541
28. Brown AS, Bottiglieri T, Schaefer CA, Quesenberry CPJR, Liu L, Bresnahan M, Susser ES (2007) Elevated prenatal homocysteine levels as a risk factor for schizophrenia. Arch Gen Psychiatry 64:980-981

29. Song H, Ueno S, Numata S, Iga J, Shibuya-Tayoshi S, Nakataki M, Tayoshi S, Yamauchi K, Sumitani S, Tomotake T, Tada T, Tanahashi T, Itakura M, Ohmori T (2007) Association between PNPO and schizophrenia in the Japanese population. Schizoph Res 97:264-270

30. Lipton SA, Kim W, Coi Y, Kumar S, D'Emilia DM, Rayadu PV, Arnelle DR, Stamler JS (1997) Neurotoxicity associated with dual actions of homocysteine at the N-methyl-D-aspartate receptor. Proc Natl Acad Sci USA 94:5923-5928

31. Ho PI, Ortiz D, Rogers E, Shea TM (2002) Multiple aspects of homocysteine neurotoxicity: glutamate excitotoxicity, kinsa hyperactivation and DNA damage. J Neurosci Res 70:694-702

32. Moore P, El-Sherbeny A, Roon P, Schoenlein PV, Ganapathy V, Smoth SB (2001) Apoptotic cell death in the mouse retinal ganlion cell layer is induced in vivo by the excitatory amino acid homocysteine. Exp Eye Res 73:45-57

33. Dimitrova KR, Degroot KW, Suyderhoud JP, Pirovic EA, Munro TJ, Wieneke J, Myers AK, Kim YD (2002) 17- $\beta$ estradiol preserves endothelial cell viability in an in vitro model of homocysteineinduced oxidative stress. J Cardiovasc Pharmacol 39:347-353

34. Yao JK, Reddy R, Mcelhinny LG, Van Kammen DP (2001) Oxidative damage and schizphrenia: an overview of the evidence and its therapeutic implications. CNS Drugs 15:287-310

35. Dietrich-Muszalska A (2004) Evaluation of the effects of different concentrations of risperidone, corresponding to the drug doses used in treatment of schizophrenic patients, on lipid peroxidation in plasma and blood platelets at in vitro studies. Psychiatria i Psychologia Kliniczna 4:215-223

36. Dietrich-Muszalska A (2005) The impact of different concentrations of clozapine on changes of lipid peroxidation in human plasma-in vitro studies. Psychiatria i Psychologia Kliniczna 1:18-25

37. Eren E, Yegin A, Yilmaz N, Herken H (2010) Serum total homocysteine, folate and vitamin B12 levels and their correlation with antipsychotic drug doses in adult male patients with chronic schizophrenia. Clin Lab 56:513-518

38. Henderson DC, Copeland PM, Nguyen DD, Borba CP, Cather C, Evins AE, Freudenreich O, Baer L, Goff DC (2006) Homocysteine levels and glucose metabolism in non-obese, non-diabetic chronic schizophrenia. Acta Psychiatr Scand 113:121-125

39. Neeman G, Blanaru M, Bloch B, Kremer I, Ermilov M, Javitt DC, Heresco-Levy U (2005) Relation of plasma glycine, serine, and homocysteine levels to schizophrenia symptoms and medication type. Am J Psychiatry 162:1738-1740

40. Malinowska J, Olas B (2011) Response of blood platelets to resveratrol during model of hyperhomocysteinemia. Platelets 22:277-283 